\title{
Control Management System Evaluation Applied in Greater Amman Municipality (GAM)
}

\author{
Nasser Assaf ${ }^{1}$, Wisam Abu Khalaf ${ }^{1}$, Abed Elkareem Alzoubi $^{1}$ \& Saed Zighan ${ }^{1}$ \\ ${ }^{1}$ Business Administration Department University of Petra, Amman, Jordan \\ Correspondence: Nasser Assaf, Department of Business Administration, University of Petra, Amman, Jordan. Tel: \\ 962-792-804-415. E-mail: nabali1983@gmail.com or nassaf@uop.edu.jo
}

Received: July 10, 2017

Accepted: August 2, 2017

Online Published: August 12, 2017

doi:10.5539/ijbm.v12n9p130

URL: https://doi.org/10.5539/ijbm.v12n9p130

\begin{abstract}
Purpose: This Paper studies the group rewards effects as a result of the tight action control system applied in (GAM), how they deal with this issue especially the fair treatment for rewards distribution and what is the criteria the organization follows at the end of the year.

GAM gives group rewards as bonuses depending on the self-opinion of the general manager believes in the ability of the team to accomplish the project, which might cause conflicts and unfair bonuses distribution among the group members.

This study diagnosis the problem and suggests solutions in order to fix the lack of confidence between the employees and the high management decisions especially with rewards, if it is not processing fairly, the organization will face un-commitment behaviors from employees to achieve the organizational objectives, in addition, they will start looking for external opportunities sooner if this issue is not solved. Employees' motivation varies among individuals, some are motivated by monetary compensations, while others by promotions and so on.

Future implications: GAM should design a group rewards system that fairly distribute the rewards among the group members. Human resource management should follow a role in evaluations of individuals performance in order to give the HR his tasks.
\end{abstract}

Keywords: action control, behaviors, group rewards, Organizations, results, Management Control System

\section{Introduction}

Greater Amman municipality (GAM) is the municipality incorporating the metropolitan region of Amman, the capital city of Jordan, which has the bulk of population of the larger Amman Governorate. The municipal council was established in 1909. In 1914, the city of Amman was made the head of Amman district .GAM provides services including planning, infrastructure development, road constructions, license issuance, health certification and inspections, equipped labs qualifications, and waste management. In addition, GAM provides services in offering public transport, parks, managing the historical attractions for visitors, to mention few.

\subsection{Vision}

A leading municipality focused in making the city of Amman an organized, modern, smart, safe, attractive, soulful, friendly, livable, and proud of its heritage and authenticity.

\subsection{Mission}

To provide high quality municipal services of excellence focused in environment, health organizational \& infrastructure dimensions while maintaining the identity of the city of Amman cultural heritage community. Development and consideration of human dimension through good planning, optimal investment of the resources, and building partnership with stakeholders. ("General Amman Municipality” 2016).

\section{Methodology}

For the purposes of this research, in depth interviews were used, which were personnel and unstructured interviews, plethora of questions were asked starting from their experience, previous and current job positions, previous and current salaries, promotions, future perspectives, working hours in addition to overtime working hours. Besides this participant's emotions, feelings, and opinions regarding a particular research subject were mentioned in the 
survey. Emotions and feelings were chosen in a scale from $0-5$ where 0 reflects complete dissatisfaction whereas 5 reflect complete satisfaction. However, participant's background was taken into consideration.

\section{Findings and Discussion}

Motivation is defined as a driving force that encourages an individual to take some actions in order to achieve particular goals, however, the motivational level varies among the individuals (Journal and Vol 2012). (Chalofsky and George 2005) explored that the performance of an individual is determined by three factors: motivation, work environment and ability to do work. Whereas (Chandrasekar 2011) examined the positive and negative impacts of workplace environment on employees morale, productivity, and job performances. He concluded that the lack of appreciation and personal decision making opportunities will result in demotivating the employees and subsequently, negatively affects the employee's job performance.

Regrettably, GAM misses the human resource management role for reward program. The top management is playing one man show for this issue. For instance, Employees are ought to call or the general manager for bonuses compensations regardless the fact that the employees have achieved their determined goals and missions. The major conflict is that the employees believe that they are not getting back what they deserve.

Employees' performances and motivation are driven by various factors including working conditions, leadership behavior, training and development opportunities, job security and companies overall policies and procedures for rewarding employee, among others.

\section{Discussion}

Various studies explained the relationship between rewards and motivation in several ways. However, this study explores the extent of the fair distribution of rewards in enhancing motivation.

Fair and just reward distribution is the only way to positively motivate employees which leads to high performance and productivity and subsequently, immensely increases the organizational efficiency. In contrast "unfair" reward distribution can lead to anxiety and de-motivation and hence, decreases employee satisfaction, performance and productivity, which eventually ultimately decreases the organizational efficiency (Eby et al. 2016).

Internal control is a primary role player with controlling the MCS. Auditing is essential to guarantee the correct and efficient control system application, however, the feedback introduced by the internal controller to the high management is vital as well, as it could help to visualize the effectiveness of the MCS.

\subsection{Management Control System (MCS)}

GAM applied a control system in which they define the areas of the required results and what should the employees do in order to achieve them. However, the concept of participation is missing here; top management did not allow lower management to participate in results definition and expectations.

GAM has a tight action control, in which they define the correct actions to be followed in each area, afterwards, the regional manager follows and assures that each employee is following instructions, however, there are some actions (technical actions) taken by professional employees such as engineers and doctors that are hard to the branch manager to follow, simply because they are too technical in a way that it becomes hard to be understood by the unspecialized employees. Therefore, the branch manager will not be able to successfully and accurately evaluate these actions, which leads to unfair performance judgment. This knowledge and professional gap will result in unsuccessful performance evaluation in group rewards. As a result, the technical staff performance feedback to the business line management will immensely underestimate the former performance with the incomplete and incomprehensive feedback.

The organization follows certain steps in recruiting, starting from hiring to selection procedures, GAM human resource management designs a job specification documented record for all the stuff working with them, in which employees can know their rights and duties. GAM has a strong personnel control, all employees including field service engineers and other specialists are enrolled in training sessions based on their qualifications and work field. The training sessions are provided from the very first day of the employees career in GAM and are provided by specialized companies ( i.e. Talal Abu-Ghazala, and others).

GAM has a strong culture control, this represents the ethnic and religious that exists among the organization staff diversity, you could find the Muslims, Christians, as well as national diversity.

"The trend that has researched into human relations has more deeply examined the analysis of the effects of individuals' behavior on the design of the control system, considering that people are moved not only by financial motivations but also by the satisfaction of other needs (Carenys 2010). 
The strong culture in the organization gives the employees a strong motivation to serve the community by helping centers to provide premium services. Believing in the organization societal and moral responsibility towards health and other sectors, gives the employees a strong incentive to provide the best.

\subsection{Advantages and Disadvantages of the MCS Applied in the Organization}

\subsubsection{Positive Implication of MCS Applied in the Organization.}

Firstly, the organization has clear and apparent desired goals, in which all of the employees believe in and try to work hard to attain all the strategic objectives. Secondly, the high management always tries to send a message to all stuff that "GAM is your house", this will make a sense of commitment inside of the employees mind, eventually, the employees will be pleasured by the good outcome. In addition, a reward system is established, in which rewards are provided for good actions and sanctions for the bad ones. In this system, GAM used a code of ethics that all employees should follow. Thirdly, training and employees orientations are working well and followed efficiently by the HR management, as mentioned above, third specialized party trained all the stuff internationally, to assure that the employees are following the latest technologies in the all fields.

Lastly, cultural harmony among employees caused by objective and common vision extensively helped in the organization success in its classification as one of the most important municipalities in the eastern region, the smelting process, all of the staff in one pot to serve the organization is one of the reasons why GAM has a successful cultural control.

\subsubsection{Disadvantages of the MCS}

Results desirability does not cover all of the business aspects, there are some departments that need to define the "good results" such as logistics support department. Employees in this department, in instance, have no clue about the desired goals of the logistics support, especially for big projects. So this should be taken into consideration.

Group rewards are not distributed equitably, estimates are subject to high management, and there is no criterion for this issue, which actually discourages the employees from working hard to attain the organization objectives because they feel that they are oppressed.

One negative side effect of the cultural control (intra-organizational transfer) is the inactive appropriate manner, some sites keeps an employee in a certain place for long periods causing frustration, lack of seriousness in work, and the lack of sincerity.

If we got the opportunity to enhance the MCS, we would update the whole MCS applied, as this system has not been updated since it was found. Many changes occurred in the markets as well as the strategies, and according to this, the MCS should be modified in order to meet the market needs as well the major expansion that took place for the organization.

We would ask for advisers to assist in the development process of the MCS. Besides this, we would chiefly consider the humanitarian side because it's the base of work and profits. In addition, we would design result-action protocol that fits with the employees' capabilities in which they can follow and achieve the required results.

It is vital to clearly communicate the organization's goals to ensure that every manager and employee understands the specific actions required of him/her to achieve organizational goals, communicate the results of actions across the organization and ensure that the management control system adjusts to changes in the environment.

Administrative controls Management could emphasis the dominant organizational system and yet, create a protocol which is the basis for everyone. A protocol would enable new employees for easy access to understand how everything works. Therefore, process setting of tactical guidelines would include short-term targets and would keep the strategic thinking in mind. Processes would set specific accountabilities, enable autonomy and decision making at every management level.

The result controls applied in the organization try to cover all result areas, it controls the employee behavior in order to reach the company goals. High management defining performance dimension in every business line, for instance, we will talk about the areas we experienced working with, the health sector line, which has a specific dimension defined for the results and it consistency with the organization objectives, the performance for health inspector is to try to cover all the public and private sectors with high techniques equipment, the business line manager has to assure that everyone in his team knows what is expected from them as a role player when they hold a new project, how should they behave to reach the desired results.

The engineers working with health sector field in labs also are highly committed to what is required to be achieved, they are responsible for installation, acceptance and validation for the projects as well as laboratory equipment maintenance. They doing their best because they have a feeling that their behavior with the customers contribute to 
the desired results.

Every year high management design targets for the health departments to reach. One reason for this success is the highly commitment of the staff working with this line as well as the good behavior from the other party, field service engineers and the logistics support, of course high management has an important role with motivating staff to attain this results.

Department of health control measured the performance in this field with satisfaction of recipient of the service and financial measures, they compared this result with the year before and found a continuous enhancement in this sector.

By the end of the year, the organization provides rewards to the staff in form of bonuses, this made the staff happy and felt that they deserved it as they had been working hard to reach the desired results of the organization.

\subsection{Evaluation of the MCS in GAM}

The current MCS is working smoothly but there are some points:

The result control needs to be updated, the plan was set, mainly covering the quantitative objectives and neglected the other targets without clear specification.

Most of the employees working with quantitative targets try to reach the goals, and they focus in the quantitative results only, this will make them ignore qualitative areas.

The action control program needs an update as well, they need to assure that all employees' behaviors are consistent with what the organization needs and that their behavior fits to the true organizational true objectives.

I think that the organization needs to design a code of conduct covering all specific results areas especially with health inspectors, engineers, and logistic support. Any delay in operation detected because of these areas among others was not covered well.

For the Personnel control, the organization has to give the new employees training about the organization's policy, procedures, and strategies, most of the new employees are not aware of the organization mission, vision and objectives.

Cultural control: (Intra organizational transfer) inactive appropriate manner, some sites keeps an employee in place for long periods, causing frustration, lack of seriousness in the work and the lack of sincerity.

\subsection{The Incentive Systems}

Most of the Incentives in the organization are short term incentive plans, the organization give all employees working in any sector an incentive in the form of bonuses in yearly basis. These rewards evaluate the employees' performance, their achievements in the previous year, how they contributed in the overall achievements, and their commitment.

GAM does not increase the basic salary, it is just a bonus or incentives come from the general manager decision and not from the human resource department. This could be unfair because it is issued by the personal convictions general manager, as well as the group rewards was planned in annual basis, and is subjected to the opinion of the general manager, thus losing equity in the distribution of bonuses among employees.

(Glynn 1996) explains organizational effectiveness as the extent to which an organization fulfills its objectives, by using certain resources and without placing strain on its members." The goal model defines organizational effectiveness referring to the extent to which an organization attains its objectives (Zammuto 1982).

(Herzberg 1964) identified two major categories of needs: "hygiene factors and motivators, which are independent and influence behavior in several ways. People that are dissatisfied with their jobs are concerned about the work environment, while satisfied individuals feel comfortable with their jobs.

GAM should consider the employee's satisfaction and dissatisfaction, because if the employees feel happy and satisfied they will try to work harder to achieve the required goals. That means GAM needs to assure that they are getting two elements of motivation: Inducing efforts, which means getting employees to work hard to reach the company true objectives. And directing efforts; employees understanding what are expected from them, the rewards bring the employees attention to the result areas need to be accomplished.

The process of providing incentives and rewards has a positive impact in employees' satisfaction scale provided equitable distribution. Previous studies have shown a relationship between incentives and employee satisfaction and found that the amount of the benefits provided by the company to its employees, whether physically or morally, reflects positively upon the sense that this contributes to the sustainability of the company and its success. 


\subsection{The Role of Controller}

Generally, the role of the controller working with management control system is to ascertain that the MCS is working well without any defect or harmful side effects coming from applying the system, prepare financial reports to the shareholder (business unit controller), supervises internal audit and accounting control procedure to ensure validity of information, and needs to assure that the system satisfies the need of the organization.

At GAM, the controller did not supply any information to the human resources department because the controller has direct connection with the general manager, this is the company problem, the controller should have a connection with all of the company departments, because he needs to collect information such as the financial ratios in order to fix any defect come as an outcome from the applying the MCS.

Internal controls are methods put in place by a company to ensure the integrity of financial and accounting information, meet operational and profitability targets, and transmit management policies throughout the organization (Tiitinen 2017).

Human resource management needs to work with the controller when they want at start the performance appraisals for the employees, the controller didn't work with HR department which make an a problem with employees performance appraisals.

For personnel control, the controller did not follow the employees or tried to understand what is the type of training they need, there is a defect in this point , as mentioned earlier, with the new employees, training will help the new people to react with organizational strategies and objectives in desired way.

\subsection{Ethical Issues Related to MCS in GAM Medico}

GAM designed a code of conduct to control the employees' behavior on the way to reach the organizational objectives. All of employees followed this code of ethics well. However, there are some loosen cases where some of employees did not care about it.

Smoking is an example, the organization banned smoking in all of the facilities, and however, some of the staff did not abide by this decision, which caused them to get sanctions.

The top management actually follows tone from the top to reinforce employees to do their best, this helps employees and give them a sense of belonging to the organization and success responsibility in term of reaching desired results.

"Establishing the right tone at the top is much more important than a system of compliance. Establishing the right tone is essential to fortifying the organization's reputation and its relationship with all stakeholders. The street is littered with institutions failures and sub-optimal performance from CEOs who have neglected to prioritize the development of a culture of integrity. The CEO is the face of the organization, the figurehead to whom employees ultimately look for vision, guidance, and leadership, Leadership derives from trust, and trust is built upon a common understanding between people (Sharpe, Albert, R., and Barabási. 2016)

\section{Conclusion}

Liability contributed to societal and moral existing in the culture of the GAM guide the staff behavior towards what is positive for the organization. Deep faith by employees and the company targets a sense of belonging, also contributed to strengthening the chances of success and improve the financial performance of the company.

If the organization desire to continue the outstanding performance they must re-evaluate and restructure the supreme departments related to personnel in order to enable employees to deliver their best and maintain their loyalty.

When there is an imbalance in the application of the control system, the management is ought to take the necessary measures to re-correct the path properly and effectively and this requires a sustained effort from control and internal or external advisors, the danger would be the unexpected losses occurring due to the loss of control of a company, which definitely, what companies are trying to avoid.

\section{References}

Carenys, J. (2010). Management Control Systems : A Historical Perspective. International Bulletin of Business Administration, 7(7), 37-54.

Chalofsky, N., \& George. (2005). Work-Life Programs and Organizational Culture: The Essence of Workplace Community.

Chandrasekar, K. (2011). Workplace Enviroment and Its Impact on Organisational Performance in Public Sector. 
International Journal of Enterprise Computing and Business Systems, 1(1), 1-19.

Eby, L., Jacquelyn, S. D., Lillian, T. E., \& Eric, S. (2016). Team-Based Rewards : Current Empirical Evidence and Directions for Future Research.

General Amman Municipality. (2016). Retrieved from http://ammancity.gov.jo/ar/gam/index.aspx

Glynn, M. A. (1996). Innovative Genius: A Framework for Relating Individual and Organizational Intelligences to Innovation. Academy of management review, 21(4), 1081-1111.

Herzberg, F. (1964). The Motivation-Hygiene Concept and Problems of Manpower." Personnel Administration.

Sharpe, M. E. H., Albert, R., \& Jeong, A. L. B.. (2016). Error and Attack Tolerance of Com-Plex Networks.

Tiitinen, P. (2017). Financial-and Business Risks Analysis of Oy Korpilampi Ab.

Zammuto, R. F. (1982). Assessing Organizational Effectiveness: Systems Change, Adaptation, and Strategy.

\section{Copyrights}

Copyright for this article is retained by the author(s), with first publication rights granted to the journal.

This is an open-access article distributed under the terms and conditions of the Creative Commons Attribution license (http://creativecommons.org/licenses/by/4.0/). 